\title{
Evaluation of Combination of Low Dose Atorvastatin Plus Ezetimibe and Aspirin in the Treatment of Atherosclerotic Vascular Disease
}

\author{
Godlaveti Vijay Narasimha Kumar ${ }^{1 *}$, Akkula Jyothi ${ }^{2}$, Chitikela P Pullaiah ${ }^{1}$, Veluri Kishore Sastha Ram³, Sandopa Dhanunjaya ${ }^{4}$, Gaddam \\ Dayanand Reddy ${ }^{1}$ \\ 'Department of Pharmacology, Siddha Central Research Institute, Arumbakkam, Chennai-600106, Tamil Nadu, INDIA. \\ ${ }^{2}$ Scientific Analyst, Molecular connections, Bengaluru, Karnataka, INDIA. \\ ${ }^{3}$ Department of Pharmacy, College of Health Sciences, Mizan Tepi University, SNPPR, ETHIOPIA. \\ ${ }^{4}$ Department of Pharmacology, Sri Padmavathi School of Pharmacy, Tirupati, Andhra Pradesh-517503, INDIA.
}

\begin{abstract}
Objective: To evaluate the effect of combination of low dose of atorvastatin plus ezetimibe and aspirin in the treatment of Atherosclerotic Vascular Disease (AVD) with special emphasis on rhabdomyolysis. Experimental Design: Thirty male rats were allocated to five groups as normal control, disease control, and test groups I, II, III. All groups except normal control group received high fat diet for 10 weeks and treatment was initiated in test groups after the completion of $4^{\text {th }}$ week, after rise in lipid levels and bodyweight of the rats when compared with normal control rats was noted. Normal control and disease control group animals received vehicle and test groups were treated with ezetimibe, $0.986 \mathrm{mg} / \mathrm{kg}$ (Clinical dose $10 \mathrm{mg}$ ) and aspirin, $7.708 \mathrm{mg} / \mathrm{kg}$ (Clinical dose $75 \mathrm{mg}$ ) along with differential doses of atorvastatin per orally. Test groups I, II, III received atorvastatin dose of $1.027 \mathrm{mg} / \mathrm{kg}, 0.770 \mathrm{mg} / \mathrm{kg}, 0.513 \mathrm{mg} / \mathrm{kg}$ p.o. respectively which were equal to clinical doses of $10 \mathrm{mg}, 7.5 \mathrm{mg}$ and $5 \mathrm{mg}$ of atorvastatin respectively. Body weight, lipid profile and grip strength were evaluated biweekly and histopathology of aorta was carried out at the end of the study. Results: The results of study reveal that test group II had significantly decreased the increased body weight, lipid levels, accumulation of lipids on the walls of aorta and incidence of rhabdomyolysis. Conclusion: The study demon-
\end{abstract}

strates that atorvastatin at clinical dose of $7.5 \mathrm{mg}$ have shown a decrease in the incidence rhabdomyolysis without loss of hypolipidemic activity when given along with clinical doses of ezetimibe and aspirin in the management of AVD.

Key words: Atherosclerotic Vascular Disease, Atorvastatin, High Fat Diet Model, Rhabdomyolysis, Statins.

Key message: Atorvastatin, at a clinical dose of $7.5 \mathrm{mg} / \mathrm{kg}$ in combination with ezetimibe and aspirin may be effectively employed in the treatment of AVD and other lipid disorders with decreased incidence of Rhabdomyolysis and increased patient compliance.

Correspondence :

G V Narasimha Kumar*, Department of Pharmacology, Siddha Central Research Institute, Anna Government Hospital Campus, Arumbakkam, Chennai-600106, Tamilnadu, INDIA.

Phone: +91-9949102404, +91-44-26244809(Ext-212)

Email: narasimha.spsp@gmail.com

DOI: 10.5530/jyp.2017.9.116

\section{INTRODUCTION}

Atherosclerotic vascular disease (AVD) is the major leading cause of the cardio vascular diseases in India and worldwide. ${ }^{1,2}$ As AVD development involves several steps, usage of combinational drugs ameliorates its progression by acting in different ways. Usage of conventional drugs has significant effect in decreasing the lipid levels. ${ }^{3}$ Statins play a major role in treatment of AVD and cardiovascular diseases. ${ }^{4} \mathrm{Co}$-administration of ezetimibe, a cholesterol absorption inhibitor along with statins resulted in decrease in elevated lipid levels. ${ }^{5}$ As AVD involves platelet aggregation in the last stage which results in severe outcomes like heart attack or stroke, anti-platelet drugs like aspirin at low doses can be used for the attenuation of consequences. Anti-inflammatory drugs may also account in reduction of generation of free radicals. The drugs which increase levels of HDL-C like niacin may improve the condition as HDL-C was involved in the reverse cholesterol transport..$^{6-8}$

At present in the market several combinational drugs are available for the treatment of AVD like Ezetimibe + Atorvastatin, Atorvastatin + clopidogrel, Ezetimibe + Simvastatin etc. In most of the combinations the common drug used is Hydroxy methylglutaryl coenzyme A (HMGCoA) reductase inhibitor, which inhibits biosynthesis of cholesterol in the liver. A moderate reduction of Cholesterol results in cell membrane domain aggregation and activation of $\mathrm{T}$ cell signalling events. ${ }^{9}$ As a result cell membrane integrity is lost and leakage of cell contents to the outside of cell occurs i.e., muscle damage occurs commonly known as rhabdomyolysis. Rhabdomyolysis is the most common side effect of (HMG-CoA) reductase inhibitors. ${ }^{10}$ Atorvastatin is the most commonly used drug of this category which is administered in the range of $10-80 \mathrm{mg}$ once daily. Studies with atorvastatin even at low dose of $10 \mathrm{mg}$ have revealed its ability to decrease the increased lipid levels but incidence of rhabdomyolysis was also observed. Thus, in spite of its hypolipidemic potential, due to muscle pain caused by rhabdomyolysis, abrupt discontinuation of atorvastatin among patients is high. As atorvastatin is commonly employed in the treatment of cardiovascular disorders along with many other categories of drugs, the problem of rhabdomyolysis needs to be solved to improve the quality of life of patients. ${ }^{11}$ Thus the hypothesis of the study was to find out the incidence of rhabdomyolysis at selected low doses of atorvastatin without losing the hypolipidemic activity in the management of AVD.

Ezetimibe is a synthetic 2-azetidinone that selectively inhibits the intestinal reabsorption of hepatic ally excreted biliary cholesterol and dietary cholesterol and its mechanism of action is complementary to that

This is an open access article distributed under the terms of the Creative Commons Attribution-Non Commercial-Share A like 4.0 License, which allows others to remix, tweak, and build upon the work non-commercially, as long as the author is credited and the new creations are licensed under the identical terms. 
of statins. ${ }^{12}$ Due to the potential risk of myopathy with statins alone, or when used in combination with fibrates or niacin, ezetimibe becomes an attractive choice to use alone or with a statin to achieve lipid targets. ${ }^{13-16}$ Further ezetimibe was only rarely reported to induce myopathy alone and also is not usually known to exacerbate statin induced myopathy. ${ }^{17}$ Aspirin is an anti-platelet agent frequently employed to manage cardiovascular disorders involving platelet aggregation. Thus, in the present study ezetimibe and aspirin were combined with atorvastatin.

The aim of the present study was to evaluate the effect of combination of low dose of atorvastatin $1.027 \mathrm{mg} / \mathrm{kg}, 0.770 \mathrm{mg} / \mathrm{kg}, 0.513 \mathrm{mg} / \mathrm{kg}$ (Human dose 10mg, $7.5 \mathrm{mg} \& 5 \mathrm{mg}$ respectively) plus Ezetimibe $0.986 \mathrm{mg} / \mathrm{kg}$ (Human dose $10 \mathrm{mg}$ ) and aspirin, $7.708 \mathrm{mg} / \mathrm{kg}$ (Human dose $75 \mathrm{mg}$ ) in the treatment of AVD in albino rats. The objective of the study was to determine the levels of triglycerides, total cholesterol, high density lipo proteins (HDL), low density lipoproteins (LDL) in the serum. Very low-density lipoproteins (VLDL) and atherogenic index were also determined based on lipid values. Grip strength was also determined at the end of the study period to know the incidence of rhabdomyolysis. Anatomical changes in the aorta were evaluated by histopathological examination.

\section{MATERIALS AND METHODS}

\section{Animals}

Adult male Wistar rats weighing 150-200 g were selected for the study and were purchased from Raghavendra enterprises, Bangalore. The animals were housed in standard environmental conditions $\left(22-28^{\circ} \mathrm{C}, 60-70 \%\right.$ relative humidity, $12 \mathrm{hr}$ light and dark cycle) and fed with rat chow and supplied with water. The experimental protocol was approved by the institutional animal ethical committee (SPSP/CPCSEA/IAEC-1016/a /2014/ 001) of Sri Padmavathi School of Pharmacy, Tirupathi, India.

\section{Drugs and Chemicals}

Atorvastatin, Ezetimibe, Aspirin, Ketamine, Xylazine, diagnostic kit for triglycerides, cholesterol-HDL kit was purchased from Span diagnostics Pvt. Ltd. India. Sudan III (Sigma Aldrich, India) and all other chemicals used were of analytical grade (Bross Scientifics, Tirupathi).

\section{Instruments}

Auto analyzer (Mispa Excel), UV-visible spectrophotometer (Analytical systems, model no: AUV 2060), Electronic balance (Shimadzu, model no: DS- 852 J), Colorimeter (Inco, model no: CL- 157), Homogenizer (Ever shine, model no: 607), Cooling centrifuge (Remi, model no: KKLO- 9013).

\section{High fat diet model}

Hypercholestremia was the major risk factor for the development of cardiovascular diseases and it involves the deposition of lipid in the intima of arteries. In the present study rats were fed with high fat diet composed of casein, cholesterol, choline, corn starch, soya bean oil, cellulose, and vitamin mixture, salt mixture was given to the rats. ${ }^{18}$

\section{Experimental design}

The total study period was 10 weeks and effect of low doses of atorvastatin plus ezetimibe and aspirin on high fat diet induced hyperlipidemia in rats was evaluated by monitoring body weights and by estimation of lipid profiles of rats biweekly. Except normal group animals remaining all animals were supplied with high fat diet. After completion of $4^{\text {th }}$ week, serum lipid profiles were monitored in animals and induction of hyperlipidemia was confirmed by the elevated lipid levels, except a decrease in HDL-C levels in experimental rats. Thus, after completion of $4^{\text {th }}$ week treatment with drugs was started in test groups and lipid profiles were estimated biweekly throughout the study period. So, duration of treatment was six weeks.

Male Wistar rats were divided into five groups six in each as follows:

Normal Control - Received normal diet, Disease Control - Received high fat diet, Test group I - Received high fat diet and atorvastatin $(1.027 \mathrm{mg} / \mathrm{kg})$ + ezetimibe $(0.986 \mathrm{mg} / \mathrm{kg})+$ aspirin $(7.708 \mathrm{mg} / \mathrm{kg})$. Test group II - Received high fat diet and atorvastatin $(0.770 \mathrm{mg} / \mathrm{kg})+$ ezetimibe $(0.986$ $\mathrm{mg} / \mathrm{kg})+$ aspirin $(7.708 \mathrm{mg} / \mathrm{kg})$. Test group III - Received high fat diet and atorvastatin $(0.513 \mathrm{mg} / \mathrm{kg})+$ ezetimibe $(0.986 \mathrm{mg} / \mathrm{kg})+$ aspirin $(7.708 \mathrm{mg} / \mathrm{kg})$. Drugs were administered to rats in test groups p.o. dissolved in Carboxy methyl cellulose (CMC).

For biochemical estimations blood samples of rats were collected from retro-orbital plexus. Rhabdomyolysis was evaluated by determining grip strength by using Rota rod apparatus at the end of study period. At the end of study period, all the animals were anaesthetized with ketamine $(100 \mathrm{mg} / \mathrm{kg})$ and xylazine $(5 \mathrm{mg} / \mathrm{kg})^{19}$ and were dissected and aortas of rats was isolated and sent to histopathological examination.

\section{Biochemical Estimations: Estimation of Lipid profile}

Triglycerides (TG) were measured by GPO/PAP method, ${ }^{20}$ total cholesterol by $\mathrm{CHOD} / \mathrm{POP}$ method, ${ }^{21}$ high density lipo protein cholesterol (HDL-C) by PEG-CHOD-PAP method by using auto-analyser. ${ }^{22}$ Very low density lipo proteins (VLDL) and atherogenic index were calculated by Freidewald's formula. ${ }^{23}$

$\mathrm{VLDL}=\mathrm{TG} / 5$

Atherogenic index $=$ TG/ HDL

\section{Grip strength of animals by Rota-rod apparatus}

Grip strength was calculated at the end of the study period. With the Rota rod apparatus muscle coordination, balance, strength and condition were tested. Rats were placed on the rod that accelerated from 5 to 45 rotations per minute within $15 \mathrm{~s}$. When a rat ran for 500 s without falling from the rod, the test session was ended. Rat that fell off within 500 s were given a maximum of two more tries. The longest running time was used for analysis. ${ }^{24}$

\section{Statistical Analysis}

All the data was expressed as mean \pm SEM (standard mean error). The statistical significance between groups was analyzed using two-way analysis of variance (ANOVA). The significance was expressed by ' $p$ ' values, and a ' $p$ ' value of $<0.05$ was taken as significant.

\section{RESULTS}

\section{Body weight}

A gradual increase in body weights was observed biweekly in disease control group animals when compared with the normal control group animals. In test group animals there was a minor decrease in body weights when compared with disease control group animals (Table 1).

\section{Lipid profile}

The levels of triglycerides, cholesterol, LDL, and VLDL were markedly increased from zero weeks to tenth week in disease control group animals when compared with the normal control group animals. In test group animals, there was a slight decrease in all these lipid levels when compared with control animals. The same trend was observed with atherogenic index also where as in case of HDL-C levels it was vice-versa. (Table 2,3). 
Table 1: Effect of low dose of Atorvastatin plus Ezetimibe and Aspirin on body weight of experimental rats

\begin{tabular}{ccccccc}
\hline Group & Zero week & Second week & Fourth week & Sixth week & Eighth week & Tenth week \\
\hline Normal Control & $120 \pm 0.8$ & $135 \pm 0.5$ & $165 \pm 0.4$ & $190 \pm 0.8$ & $200 \pm 0.8$ & $210 \pm 0.7$ \\
Disease Control & $125 \pm 0.9$ & $150 \pm 0.6^{*}$ & $190 \pm 0.7^{*}$ & $251 \pm 0.5^{*}$ & $274 \pm 0.3^{*}$ & $298 \pm 0.7^{*}$ \\
Test group-I & $122 \pm 0.8$ & $152 \pm 0.8$ & $192 \pm 0.5$ & $205 \pm 0.5^{* *}$ & $221 \pm 0.7^{* *}$ & $215 \pm 0.5^{* *}$ \\
Test group-II & $125 \pm 0.6$ & $151 \pm 0.6$ & $189 \pm 0.6$ & $214 \pm 0.5^{* *}$ & $225 \pm 0.5^{* *}$ & $218 \pm 0.7^{* *}$ \\
Test group-III & $123 \pm 0.7$ & $155 \pm 0.7$ & $191 \pm 0.7$ & $235 \pm 0.7^{* *}$ & $230 \pm 0.5^{* *}$ & $223 \pm 0.5^{* *}$ \\
\hline
\end{tabular}

All values are shown as Mean $\pm \mathrm{SEM}$ and $\mathrm{n}=6,{ }^{*}$ indicate $p<0.05$, when compared to Normal control, ${ }^{* *}$ indicate $p<0.05$, when compared to disease control.

Table 2: Effect of low dose of Atorvastatin plus Ezetimibe and Aspirin on Triglyceride, Total Cholesterol and LDL-C levels in experimental rats

\begin{tabular}{|c|c|c|c|c|c|c|c|}
\hline Group & Para-meter & Zero week & Second week & Fourth week & Sixth week & Eighth week & Tenth week \\
\hline \multirow{3}{*}{$\begin{array}{l}\text { Normal } \\
\text { Control }\end{array}$} & TG & $47.8 \pm 0.6$ & $59.4 \pm 0.5$ & $63.6 \pm 0.4$ & $65.3 \pm 0.4$ & $69.7 \pm 0.4$ & $75.6 \pm 0.4$ \\
\hline & $\mathrm{TC}$ & $130.8 \pm 0.5$ & $141.4 \pm 0.5$ & $144.3 \pm 0.3$ & $151 \pm 0.7$ & $158.4 \pm 0.4$ & $152.3 \pm 0.5$ \\
\hline & LDL & $79.4 \pm 0.3$ & $79.4 \pm 0.4$ & $82.7 \pm 0.3$ & $88.4 \pm 0.3$ & $81.2 \pm 0.3$ & $84.1 \pm 0.3$ \\
\hline \multirow{3}{*}{$\begin{array}{l}\text { Disease } \\
\text { Control }\end{array}$} & TG & $49.7 \pm 0.3$ & $74.8 \pm 0.3^{*}$ & $121.5 \pm 0.7^{*}$ & $183.9 \pm 0.5^{*}$ & $208.9 \pm 0.4^{*}$ & $241.7 \pm 0.6^{*}$ \\
\hline & $\mathrm{TC}$ & $127.4 \pm 0.4$ & $149.3 \pm 0.4^{\star}$ & $192.5 \pm 0.4^{*}$ & $229.9 \pm 0.4^{*}$ & $251.4 \pm 0.5^{\star}$ & $283.4 \pm 0.4^{*}$ \\
\hline & LDL & $77.3 \pm 0.4$ & $92.4 \pm 0.4^{*}$ & $132.3 \pm 0.3^{*}$ & $160.3 \pm 0.3^{*}$ & $179.4 \pm 0.2^{\star}$ & $207.4 \pm 0.3^{*}$ \\
\hline \multirow{3}{*}{ Test group-I } & TG & $49.3 \pm 0.6$ & $77.7 \pm 0.4$ & $119.2 \pm 0.3$ & $117.4 \pm 0.9^{* *}$ & $119.1 \pm 0.6^{* *}$ & $127.5 \pm 0.4^{* *}$ \\
\hline & $\mathrm{TC}$ & $129.6 \pm 0.3$ & $147.4 \pm 0.4$ & $191.3 \pm 0.4$ & $183.1 \pm 0.4^{\star *}$ & $190.5 \pm 0.3^{* *}$ & $180.5 \pm 0.3^{* *}$ \\
\hline & LDL & $76.2 \pm .3$ & $90.4 \pm 0.3$ & $130.3 \pm 0.4$ & $110.4 \pm 0.2^{* *}$ & $102.3 \pm 0.3^{* *}$ & $98.5 \pm 0.2^{* *}$ \\
\hline \multirow{3}{*}{ Test group-II } & TG & $47.5 \pm 0.5$ & $79.4 \pm 0.4$ & $116.3 \pm 0.4$ & $118 \pm 0.4^{* *}$ & $124.4 \pm 0.6^{* *}$ & $132.4 \pm 0.2^{* *}$ \\
\hline & $\mathrm{TC}$ & $126.6 \pm 0.5$ & $144.7 \pm 0.4$ & $195.7 \pm 0.4$ & $192.5 \pm 0.4^{* *}$ & $209.7 \pm 0.3^{* *}$ & $191.2 \pm 0.3^{* *}$ \\
\hline & LDL & $76.2 \pm 0.4$ & $89.5 \pm 0.4$ & $129.2 \pm 0.2$ & $119.3 \pm 0.2^{\star *}$ & $108.4 \pm 0.4^{* *}$ & $110.4 \pm 0.3^{* *}$ \\
\hline \multirow{3}{*}{ Test group-III } & TG & $46.9 \pm 0.6$ & $78.4 \pm 0.4$ & $116.9 \pm 0.2$ & $128.6 \pm 0.4^{\star *}$ & $132.2 \pm 0.8^{* *}$ & $149.8 \pm 0.3^{* *}$ \\
\hline & $\mathrm{TC}$ & $124.4 \pm 0.4$ & $149.52 \pm 0.9$ & $197.6 \pm 0.4$ & $205.5 \pm 0.4^{* *}$ & $224.6 \pm 0.3^{* *}$ & $217.3 \pm 0.5^{* *}$ \\
\hline & LDL & $74.5 \pm 0.2$ & $88.3 \pm 0.4$ & $131.3 \pm 0.3$ & $148.6 \pm 0.2^{\star *}$ & $144.4 \pm 0.3^{* *}$ & $159.6 \pm 0.2^{* *}$ \\
\hline
\end{tabular}

All values are shown as Mean $\pm \mathrm{SEM}$ and $\mathrm{n}=6$, ${ }^{*}$ indicate $p<0.05$, when compared to Normal control, ${ }^{*}$ indicate $p<0.05$, when compared to disease control. TG=Triglycerides, TC=Total Cholesterol, LDL-C= Low Density Lipoprotein- Cholesterol

Table 3: Effect of low dose of Atorvastatin plus Ezetimibe and Aspirin on HDL-C, VLDL-C and Atherogenic Index in experimental rats

\begin{tabular}{|c|c|c|c|c|c|c|c|}
\hline Group & Para-meter & Zero week & Second week & Fourth week & Sixth week & Eighth week & Tenth week \\
\hline \multirow{3}{*}{$\begin{array}{l}\text { Normal } \\
\text { Control }\end{array}$} & HDL & $41.2 \pm 0.3$ & $42.4 \pm 0.4$ & $41.5 \pm 0.5$ & $45.8 \pm 0.4$ & $47.7 \pm 0.4$ & $42.8 \pm 0.8$ \\
\hline & VLDL & $9.5 \pm 0.3$ & $11.9 \pm 0.3$ & $12.6 \pm 0.3$ & $13.4 \pm 0.4$ & $14.1 \pm 0.4$ & $15.0 \pm 0.5$ \\
\hline & AI & $1.21 \pm 0.3$ & $1.4 \pm 0.3$ & $1.5 \pm 0.3$ & $1.1 \pm 0.3$ & $1.4 \pm 0.1$ & $1.7 \pm 0.06$ \\
\hline \multirow{3}{*}{$\begin{array}{l}\text { Disease } \\
\text { Control }\end{array}$} & HDL & $41.8 \pm 0.8$ & $41.7 \pm 0.4$ & $36.2 \pm 0.3^{*}$ & $31.8 \pm 0.3^{*}$ & $29.4 \pm 0.4^{*}$ & $27.4 \pm 0.4^{*}$ \\
\hline & VLDL & $9.9 \pm 0.4$ & $14.6 \pm 0.3^{*}$ & $24.6 \pm 0.4^{*}$ & $36.2 \pm 0.4^{*}$ & $41.0 \pm 0.4^{*}$ & $48.2 \pm 0.4^{*}$ \\
\hline & AI & $1.25 \pm 0.3$ & $1.7 \pm 0.2^{*}$ & $3.3 \pm 0.2^{*}$ & $5.8 \pm 0.2^{*}$ & $7.1 \pm 0.2^{*}$ & $8.8 \pm 0.2^{*}$ \\
\hline \multirow{3}{*}{ Test group-I } & $\mathrm{HDL}$ & $40.6 \pm 0.3$ & $41.9 \pm 0.3$ & $38.2 \pm 0.2$ & $45.5 \pm 0.4^{* *}$ & $51.4 \pm 0.4^{* *}$ & $56.2 \pm 0.3^{* *}$ \\
\hline & VLDL & $9.8 \pm 0.3$ & $15.2 \pm 0.2$ & $23.5 \pm 0.4$ & $23.4 \pm 0.4^{\star *}$ & $23.7 \pm 0.4^{\star *}$ & $25.2 \pm 0.4^{* *}$ \\
\hline & AI & $1.24 \pm 0.3$ & $1.8 \pm 0.3$ & $3.2 \pm 0.1^{* *}$ & $2.5 \pm 0.3^{* *}$ & $2.3 \pm 0.3^{* *}$ & $2.2 \pm 0.3^{\star *}$ \\
\hline \multirow{3}{*}{ Test group-II } & HDL & $40.7 \pm 0.4$ & $40.7 \pm 0.2$ & $36.2 \pm 0.2$ & $43.2 \pm 0.2^{\star \star}$ & $46.9 \pm 0.3^{* *}$ & $49.78 \pm 0.3^{* *}$ \\
\hline & VLDL & $9.4 \pm 0.3$ & $15.4 \pm 0.3$ & $25.6 \pm 0.4$ & $23.5 \pm 0.3^{\star *}$ & $24.4 \pm 0.8^{\star *}$ & $26.5 \pm 0.3^{* *}$ \\
\hline & AI & $1.1 \pm 0.2$ & $1.92 \pm 0.2$ & $3.2 \pm 0.2^{\star *}$ & $2.7 \pm 0.2^{\star \star}$ & $2.4 \pm 0.2^{\star *}$ & $2.6 \pm 0.3^{\star *}$ \\
\hline \multirow{3}{*}{ Test group-III } & HDL & $41.4 \pm 0.3$ & $40.6 \pm 0.4$ & $37.2 \pm 0.3$ & $38.2 \pm 3^{* *}$ & $40.2 \pm 0.3^{* *}$ & $39.0 \pm 0.7^{* *}$ \\
\hline & VLDL & $9.3 \pm 0.4$ & $15.2 \pm 0.4$ & $23.5 \pm 0.5$ & $25.7 \pm 0.4^{\star *}$ & $26.3 \pm 0.4^{* *}$ & $30.4 \pm 0.3^{\star *}$ \\
\hline & AI & $1.17 \pm 0.1$ & $1.90 \pm 0.1$ & $3.1 \pm 0.4^{\star *}$ & $3.3 \pm 0.1^{\star *}$ & $3.3 \pm 0.1^{\star \star}$ & $3.8 \pm 0.04^{* *}$ \\
\hline
\end{tabular}

All values are shown as Mean \pm SEM and $\mathrm{n}=6,{ }^{*}$ indicate $p<0.05$, when compared to Normal control, ${ }^{* *}$ indicate $p<0.05$, when compared to disease control. HDL-C= High density lipoprotein Cholesterol, VLDL-C $=$ Very low density lipoprotein Cholesterol, AI $=$ Atherogenic Index. 
Table: 4 Effect of low dose of Atorvastatin plus Ezetimibe and Aspirin on grip strength in experimental rats.

\begin{tabular}{cc}
\hline Group & Time $(\mathrm{sec})$ \\
\hline Normal Control & $402.5 \pm 8.732$ \\
Disease Control & $286.2 \pm 3.859^{*}$ \\
Test group-I & $188.7 \pm 4.080^{*}$ \\
Test group-II & $303.5 \pm 4.041^{*}$ \\
Test group-III & $385.3 \pm 2.011^{*}$ \\
\hline
\end{tabular}

All values are shown as Mean \pm SEM and $\mathrm{n}=6,{ }^{*}$ indicate $p<0.05$, when compared to Normal control

\section{Grip Strength}

Grip strength of animals was estimated at the end of study. There was greater grip strength in animals of test group I and II when compared with the animals of test group III (Table 4).

\section{Histopathology of Aorta}

Histopathological examination (magnification-10X) of abdominal aorta in normal control group animals had shown no abnormality (Figure 1.a). Disease control group animals had shown intimal thickening, and accumulation of lipids in the aorta (Figure 1.b). There was a slight decrease in lipid accumulation in test group animals when compared to disease control group animals (Figure $2 \mathrm{ab} \&$ Figure $3 \mathrm{a}$ ).

\section{DISCUSSION}

Currently AVD is effectively managed with a combination therapy which may include a statin, ezetimibe, clopidogrel or aspirin and niacin. As statins helps in reduction of hepatic cholesterol synthesis, they play a major role in the treatment of AVD and other lipid disorders. ${ }^{25}$ Among statins atorvastatin is the most prescribed drug to the patients and the dosing may be continued up to six months or more based on serum cholesterol levels. The most important drawback of statins is rhabdomyolysis causing abrupt discontinuation by patients. ${ }^{26}$ Ezetimibe given at a dose of $10 \mathrm{mg}$ once daily is a cholesterol absorption inhibitor through duodenal cells by inhibiting Niemann Pick $\mathrm{C}_{1}$ like protein which is a transporter for cholesterol. Ezetimibe usage in AVD condition can improve the patient condition by decreasing the plasma concentration of cholesterol. ${ }^{27}$ Aspirin, at a dose of 75-100 mg selectively inhibits cyclooxygenase- 1 in platelets by acetylating a single serine residue at position 529 in cyclooxygenase-1 leading to inhibition of Thromboxane $\mathrm{A}_{2}$ production, thus resulting in anti-platelet activity. ${ }^{28}$

Studies with atorvastatin at its lowest dose i.e. $10 \mathrm{mg}$ in the management of cardiovascular disorders have shown that there is a prominent decrease in lipid levels with incidence of rhabdomyolysis. ${ }^{11}$ Patients will be benefited if atorvastatin can retain its hypolipidemic potential at doses less than 10mg without causing rhabdomyolysis. Thus, in the present study, we contemplated to test whether atorvastatin at selected doses i.e., $10 \mathrm{mg}$, $7.5 \mathrm{mg}$ and $5 \mathrm{mg}$, was able to produce rhabdomyolysis, along with ezetimibe (10mg) and aspirin $(75 \mathrm{mg})$ in the management of AVD, without losing its hypolipidemic potential in albino rats. $10 \mathrm{mg}$ dose was included in the study as it is the lowest therapeutic dose of atorvastatin. Rat doses of the above mentioned human doses were calculated as per Jang-Woo Shin et al., $2010 .^{29}$

In the present study high fat diet model was used to induce hypercholestremia as it has same pathophysiology in the development of AVD as that of humans. A high fat diet containing cellulose, choline, cholesterol, soyabean oil, casein, salt mixture, vitamin mixture was supplied to the male wistar rats throughout the study period of 10 weeks except for the
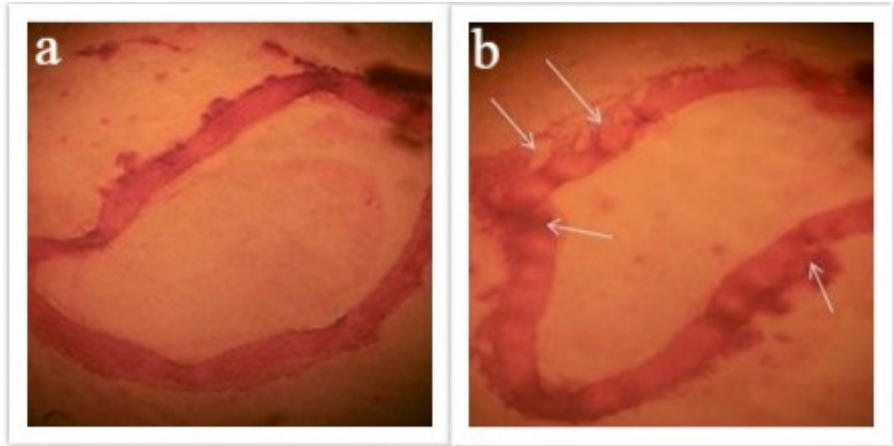

Figure 1: a. Histopathology of aorta of normal group rats showing normal texture (10X) B. Histopathology of aorta of disease control group rats characterised by thickness relative to normal control rats (10X). Magnification scale: $100 \mu \mathrm{m}$
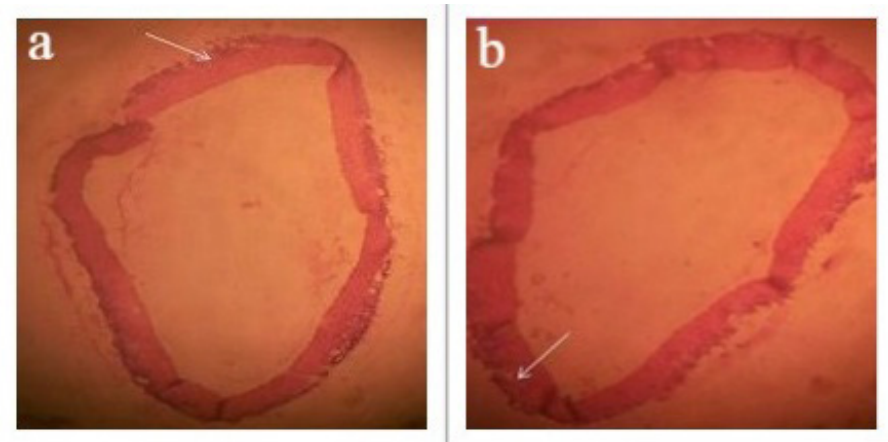

Figure 2: a. Histopathology of aorta of test group-I rats (10X) showing absence of lipid deposits b. Histopathology of aorta of test group-II rats (10X) showing absence of lipid deposits. Magnification scale: $100 \mu \mathrm{m}$

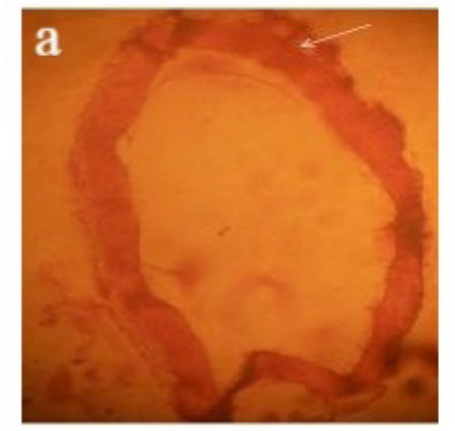

Figure 3: a. Histopathology of aorta of test group-III rats (10X) showing moderate accumulation of lipids. Magnification scale: $100 \mu \mathrm{m}$

normal control group animals. Casein is a milk protein which can increase the levels of lipids in the triglyceridemic condition. Cholesterol can directly increase the plasma levels of cholesterol after absorbing through duodenal cells into the systemic circulation. Soyabean oil when taken in normal quantities it has protective effect against free radical generation but in higher amounts triglyceridemic condition will result. Choline intake directly increases the levels of lipids when taken. ${ }^{12}$

High fat diet was given to the rats of all groups except normal control group throughout the study period. Treatment was initiated after four weeks by which there was a prominent increase in body weight, triglycerides, cholesterol, LDL, VLDL and decrease in HDL in rats of all groups 
Kumar et al: Combination of Low Dose Atorvastatin plus Ezetimibe and Aspirin in the Treatment of Atherosclerotic Vascular Disease

except normal control group. At the end of the treatment schedule, body weight, triglycerides, cholesterol, LDL, VLDL values and atherogenecity index were high and HDL decreased in disease control group animals when compared to normal control group animals. Test group animals showed a decrease in body weight, lipid values and atherogenecity with an elevation in HDL levels when compared to disease control. Within the test groups, test group I showed a prominent hypolipidemic effect, group-II showed a moderate effect and group-III showed low effect. From this it is evident that atorvastatin at a dose of $5 \mathrm{mg}$ human dose is having low hypolipidemic potential.

Evaluation of muscle strength is an essential step for researching neuromuscular disorders and multiple methods have been developed to measure muscle strength in rodents. Among these methods, grip strength tests are more convenient and give less stress to animals than other tests. ${ }^{30}$ In grip strength test, disease control animals showed moderate grip strength when compared to normal control group animals. Test group animals showed decrease in the grip strength when compared to normal group animals but grip strength was high among Group-III, moderate in Group-II and low in group-I. This gives evidence that there is a decreased incidence of rhabdomyolysis in test groups II and III. From this atorvastatin at a dose of $10 \mathrm{mg}$ human dose is causing rhabdomyolysis. Histopathological examinations of aorta have shown that there was no lipid accumulation in normal group animals and there was a marked loading of lipids in disease control group animals when compared to normal control group animals. Test group animals showed a decrease in lipid accumulation but effect was pronounced in group I \& II animals compared to group-III animals. Group-III animals showed moderate accumulation of lipids owing to low dose of atorvastatin employed (5 mg human dose).

Body weight changes, biochemical parameters, histopathological studies and grip strength studies, reveal that rats treated with atorvastatin at a dose of $0.770 \mathrm{mg} / \mathrm{kg}$ (clinical dose $-7.5 \mathrm{mg}$ ) along with ezetimibe and aspirin have shown similar lipid profile, decreased atherogenicity as in rats treated with $1.027 \mathrm{mg} / \mathrm{kg}$ atorvastatin (clinical dose - $10 \mathrm{mg}$ ) along with ezetimibe and aspirin with low incidence of rhabdomyolysis.

\section{CONCLUSION}

Statins are the first line therapy drugs employed in the treatment of lipid abnormalities but the most common adverse effect observed is rhabdomyolysis at therapeutic doses used, causing abrupt discontinuation by the Patient's due to muscle pain. The present study demonstrates that $7.5 \mathrm{mg}$ clinical dose $(0.770 \mathrm{mg} / \mathrm{kg}$ rat dose $)$ of atorvastatin along with ezetimibe and aspirin may be used effectively to treat AVD and other lipid abnormalities with decreased incidence of rhabdomyolysis which may augment patient compliance of atorvastatin. Further clinical studies are warranted to evaluate the same in the management of AVD and other lipid disorders which can improve the quality of life of patients.

\section{ACKNOWLEDGEMENT}

Authors would like to express gratitude towards Prof. D. Ranganayakulu, Prof. C. Sridhar, Dr. B .Pushpakumari of Sri Padmavathi School of Pharmacy, Tirupathi and Dr. D. Sujatha, SPMVV, Tirupathi for their valuable inputs and support for the completion of the study.

\section{CONFLICT OF INTEREST}

None

\section{ABBREVIATIONS USED}

ANOVA: Analysis of variance; AVD: Atherosclerotic Vascular Disease; CPCSEA: Committee for the purpose of Control and Supervision of
Experiments on Animals; HDL: High Density lipo Proteins ; HMGCoA: Hydroxy methylglutaryl coenzyme A; IAEC: Institutional Animal Ethics Committee; LDL: Low Density Lipoproteins; PO: Per Oral; SEM: Standard Mean Error; VLDL: Very low density lipoproteins.

\section{REFERENCES}

1. Das SW, Hakim AB, Mittal AJ. Study of the antihyperlipidemic, antioxidative and antiatherogenic activity of Aegle marmelos linn. in rabbit receiving high fat diet. Asian J Pharm Clin Res 2012;5(4):69-72.

2. Barquera S, Pedroza-Tobías A, Medina C, Hernandez-Barrera L, Bibbins-Domingo K, Lozano R, et al. Global overview of the epidemiology of atherosclerotic cardiovascular disease. Arch Med Res 2015;46:328-38.

3. Shattat GF. A review article on hyperlipidemia: types, treatments and new drug targets. Biomed Pharmacol J. 2015;7(1):399-409.

4. Pasterkamp G, van Lammeren GW. Pleiotropic effects of statins in atherosclerotic disease. Expert Rev Cardiovasc Ther. 2010;8(9):1235-7.

5. Grigore L, Norata GD, Catapano AL. Combination therapy in cholesterol reduction: focus on ezetimibe and statins. Vascular health and risk management. 2008;4(2):267.

6. Paul A, Calleja L, Camps J, Osada J, Vilella E, Ferré N, et al. The continuous administration of aspirin attenuates atherosclerosis in apolipoprotein E-deficient mice. Life Sci. 2000;68(4):457-65.

7. Steer KA, Wallace TM, Bolton $\mathrm{CH}$, Hartog M. Aspirin protects low density lipoprotein from oxidative modification. Heart. 1997;77(4):333-7.

8. Berger JS, Lala A, Krantz MJ, Baker GS, Hiatt WR. Aspirin for the prevention of cardiovascular events in patients without clinical cardiovascular disease: a meta-analysis of randomized trials. Am Heart J. 2011;162:115-24.

9. Dinic J, Ashrafzadeh P, Parmryd I. Actin filaments attachment at the plasma membrane in live cells cause the formation of ordered lipid domains. Biochimica Et Biophysica Acta (BBA)-Biomembranes. 2013;1828(3):1102-11.

10. Khan FY. Rhabdomyolysis: a review of the literature. Neth J Med. 2009;67(9):272-83.

11. Constance C, Ben-Yehuda O, Wenger NK, Zieve F, Lin J, Hanson ME, et al. Atorvastatin $10 \mathrm{mg}$ plus ezetimibe versus titration to atorvastatin $40 \mathrm{mg}$ : attainment of European and Canadian guideline lipid targets in high-risk subjects $\geq$ 65 years. Lipids Health Dis. 2014;13(1):1-8.

12. Toth PP, Davidson MH. Cholesterol absorption blockade with ezetimibe. Current Drug Targets-Cardiovascular \& Hematological Disorders. 2005;5(6):455-62.

13. Thompson PD, Clarkson $\mathrm{P}$, Karas RH. Statin-associated myopathy. JAMA. 2003;289(13):1681-90.

14. Shek A, Ferrill MJ. Statin-fibrate combination therapy. Ann Pharmacother. 2001;35(7-8):908-17.

15. Reaven P, Witztum JL. Lovastatin, nicotinic acid, and rhabdomyolysis. Ann Intern Med. 1988;109(7):597-8.

16. Norman DJ. Myolysis and acute renal failure in a heart-transplant recipient receiving lovastatin. N Engl J Med. 1988;318:46-7.

17. Brahmachari B, Chatterjee S. Myopathy induced by statin-ezetimibe combination: Evaluation of potential risk factors. Indian J Pharmacol. 2015;47(5):563.

18. Matos SL, Paula HD, Pedrosa ML, Santos RC, Oliveira EL, Chianca Júnior DA, et al. Dietary models for inducing hypercholesterolemia in rats. Braz Arch Biol Technol. 2005;48(2):203-9.

19. Gerhard Vogel H. Anti-Atherosclerotic Activity. In. Gerhard Vogel H, editor. Drug Discovery and Evaluation: Pharmacological Assays. $3^{\text {rd }}$ ed. Springer Publications; 2008. P. 1661-1771.

20. Fossati $P$, Prencipe L. Serum triglycerides determined colorimetrically with an enzyme that produces hydrogen peroxide. Clin Chem. 1982;28(10):2077-80

21. Allain CC, Poon LS, Chan CS, Richmond WF, Fu PC. Enzymatic determination of total serum cholesterol. Clin Chem. 1974;20(4):470-5.

22. Grillo F, Izzo C, Mazzotti G, Murador E. Improved method for determination of high-density-lipoprotein cholesterol II. Enzymic determination of cholesterol in high-density lipoprotein fractions with a sensitive reagent. Clin Chem. $1981 ; 27(3): 375-9$

23. Friedewald WT, Levy RI, Fredrickson DS. Estimation of the concentration of low-density lipoprotein cholesterol in plasma, without use of the preparative ultracentrifuge. Clin Chem. 1972;18(6):499-502.

24. Urmilesh Jha, Prites Chhajed, Rajesh Oswal, Tushar T Shelke. Skeletal muscle relaxant activity of methanolic extract of Parthenium hysterophorus L. leaves in swiss albino mice. Int J Pharm Life Sci. 2011;2:1211-13.

25. Ansell BJ, Watson KE, Fogelman AM, Navab M, Fonarow GC. High-density lipoprotein function. J Am Coll Cardiol. 2005;46(10):1792-8.

26. Schachter M. Chemical, pharmacokinetic and pharmacodynamic properties of statins: an update. Fundam Clin Pharmacol. 2005;19(1):117-25.

27. Charles Z, Pugh E, Barnett D. Ezetimibe for the treatment of primary (heterozygous-familial and non-familial) hypercholesterolaemia: NICE technology appraisal guidance. Heart. 2008;94(5):642-3

28. Chen CN, Chen HR, Chang HI, Yen CK, Lai CJ, Lee KH, et al. Relationship between the antiplatelet effect of aspirin and serum VCAM-1 concentration in pa- 
tients at high risk for cardiovascular events. Acta Cardiol Sin. 2010;26(1):28-36.

29. Shin JW, Seol IC, Son CG. Interpretation of animal dose and human equivalent dose for drug development. J Korean Oriental Med. 2010;31(3):1-7.
30. Hikari T, Koichi Y, Satoko N, Tadakatsu I, Hirotsugu T, Mikiyasu S, et al. Modified forelimb grip strength test detects aging-associated physiological decline in skeletal muscle function in male mice. Sci Rep. 2017;7:1-9.

Article History: Submission Date : 12-04-2017 ; Revised Date : 28-05-2017; Acceptance Date : 15-07-2017.

Cite this article: Narasimha KGV, Jyothi A, Pullaiah CP, Ram VKS, Dhanunjaya S, Reddy GD. Evaluation of Combination of Low Dose Atorvastatin plus Ezetimibe and Aspirin in the Treatment of Atherosclerotic Vascular Disease. J Young Pharm. 2017;9(4):610-5. 